\section{The big Big Bang book}

John Maddox

Stephen Hawking's A Brief History of Time has been the publishing phenomenon of the year. The book may have more buyers than readers but does that matter?

Tirose who worry about the supposed public ignorance of science must surely be comforted to know that in the United States there are now in circulation 600,000 copies of Professor Stephen Hawking's book A Brief History of Time. For weeks now, the book has been in the best-seller lists, in Britain (where Bantam Press says it has 150,000 copies in print) as well as the United States. With Christmas on the way, sales could easily exceed $1,000,000$ within a year of first publication. Is not this vast circulation of a tract (in the best sense) offering up-to-date if provisional answers to all reasonable questions about the origin, mechanism and fate of the Universe proof of public hunger for enlightenment and a sign that the hunger has been substantially satisfied?

Sad to say, most of those to whom I have been putting questions like these during the past few days seem not persuaded that Hawking's book is a sign that public indifference towards science (and the hostility that indifference breeds) is nearing its end. Indeed, and this may be sadder still, the most common reaction is best described as professional competitiveness, or otherwise as envy: people look abstracted as they multiply $\$ 18.50$ by 600,000 and then take 10 or 15 per cent of that.

Curiously, among roughly a score of people I have questioned during a visit to California (not all of them scientists) I found none who did not know of the book, three who owned a copy and none who had yet read it. This seems odd for a volume of only 198 pages whose author's estimate of the reading-time can be inferred, from his statement that 1,000 calories of nutriment will be required to capture its information content, as roughly half a day.

Indeed, there is a strange embarrassment about the book. People say it is a 'cult' book, or describe Professor Hawking as a 'cult' figure. In California, well-used to the coming and going of gurus differing in persuasions and persuasiveness, this explanation may seem natural. But even California cannot have absorbed all those 600,000 copies. The plain truth is that Professor Hawking's way of life and his reputation have gripped the public imagination in a way that is almost as phenomenal as the sales of his book.

The details are well-known and are retold in passing in the text. Hawking developed motor neuron disease while still a graduate student, and has been in a wheel-chair ever since. His capacity for speech, already seriously impaired for 20 years, was entirely destroyed four years ago by a tracheotomy, with the result that he now communicates by means of a word processor linked to a speech synthesizer.
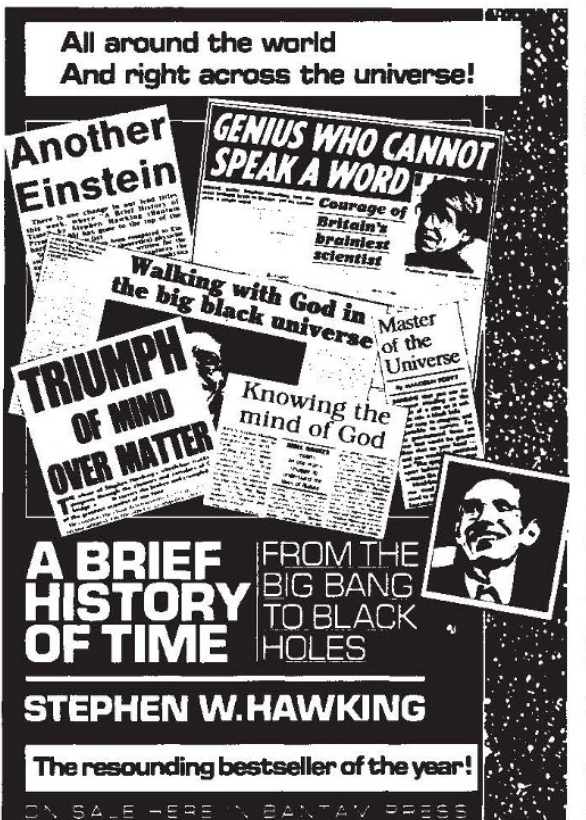

Sales talk - Bantam's poster for the British edition of Hawking's book.

During this long period, he has been extraordinarily productive of innovation in gravitation theory and quantum gravity, taking it as a guiding principle that his disability will not prevent him behaving as would any other creative scientist. One measure of his courage is that he is as likely to be found at meetings in Moscow or Texas as in Cambridge (England). where he holds Newton's chair in mathematics.

Hawking 's hold on the public imagination is exemplified by the tale told last week by a Californian Englishman who explained that a chance acquaintance at a motor-service station. learning that he was a scientist, had asked "Do you know Professor Hawking? He's my hero". But an academic architect, whose trust in science is not much more robust than that of a rabbit in a fox, Saw Hawking 's hold on his students as a "Strangelove complex". "This", he said, "is what scientists want to be like, brains driving speech synthesizers".

There is no doubt that the vividness of these images has been engendered by the publicity Hawking personally has given to his book. A few months ago, for example, he made a tour of campuses in the United States, everywhere speaking to crowded auditoria. But now the more envious of Hawking's colleagues are saying that his publishers are exploiting his disabilities commercially, which is the silliest canard. People who write books have an obligation (not merely to their publishers, but to themselves) to ensure wide circulation.

The more serious question is that of what the influence of the book will be. It is remarkable that there should seem to be so many buyers and so few who acknowledge being readers. Is it possible that the book itself is not as appealing as its title? Sadly, re-reading the book I still have the impression that it does not live up to its promise to explain the whole of recent cosmology (inflation, string theory and all that) to the ordinary person willing to make some effort.

My disappointment - shared. I see, by Professor Owen Gingerich (p.288) - is all the greater because Hawking's text begins so well. He teases the reader with questions that should spring to mind. Why did not people think that the Universe is expanding (or contracting) until the $1920 \mathrm{~s}$ ? What would the Universe be like if Newton's law of gravitation were not an inversesquare law? Special relativity is splendidly explained, but there are many among Hawking's general readership who will ask whether the old twin-paradox (that the returning traveller ages less than his stay-at-home twin) is completely cxorcised by the remark that there is no such thing as absolute time. The first dozen or so pages of the text have a freshness that soon melts away as the complexity of the ideas is magnified with the passage of time. I doubt that even the most diligent readers. for example, will know what particle spin means if they did not have an inkling before embarking on the book.

Yet Hawking's chief message does indeed shine through: the gravitation theory of general relativity is so modified by quantum theory that the literal singularity that occasions the Big Bang would not have occurred, the behaviour of the Universe would not necessarily have been discontinuous at the time supposed to be its beginning and, as a result, one can speculate about what went before. That, of course, is a message fit for a guru. It is also an extremely important message for us all. Perhaps it will not matter if only a fraction of the 600,000 books in circulation are read cover-to-cover if the suspicion begins to form in people's minds that the Big Bang in its strict interpretation is just another fairy story.

John Maddox is Editor of Nature. 